\title{
Evaluation of Nanosilver Solution Stability against Streptococcus mutans, Staphylococcus aureus and Pseudomonas aeruginosa
}

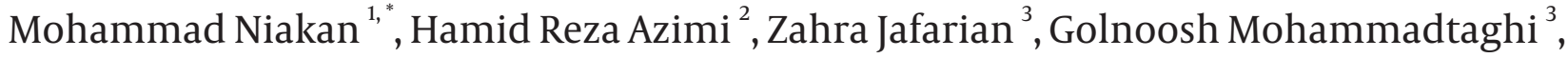 \\ Sarah Niakan ${ }^{4}$, Seyed Mostafa Mostafavizade ${ }^{5}$ \\ 1 Department of Microbiology, Medicine Faculty Shahed University, Tehran, IR Iran \\ 2 Department of oral and maxillofacial surgery, Dentistry faculty, Shahed University, Tehran, IR Iran \\ 3 Dentistry Faculty, Shahed University, Tehran, IR Iran \\ 4 Faculty of Specialized Veterinary medicine Sciences and Research Branch, Islamic Azad University, Tehran, IR Iran. \\ 5 Medicine Faculty, Shahed University, Tehran, IR Iran \\ ${ }^{*}$ Corresponding author: Mohammad Niakan, Department of Microbiology, Medicine Faculty Shahed University, Tehran, IR Iran. Tel: 9821-88964792, Fax: 9821-88966310, E-mail: \\ niakan@shahed.ac.ir.
}

Received: October 13, 2012; Revised: March 14, 2013; Accepted: March 25, 2013

\begin{abstract}
Background: Nanosilver compounds are admired in different fields of medicine and industry, due to their unique antibacterial properties. Maximum contact of silver particles in nanosilver suspension causes increasing antibacterial effect of this compound. Objectives: The aim of this study was to evaluate the stability of antibacterial properties of nanosilver solution during a period of 9 months against Streptococcus mutans, Staphylococcus aureus and Pseudomonas aeruginosa.

Materials and methods: In this in vitro study, the antibacterial effect of serial concentrations of nanosilver solution and amoxicillin antibiotic as control group on the standard bacteria S. mutans, S. aureus and P. aeruginosa were measured in 0-3-6-9 month period by Disc diffusion methods.

Results: The antibacterial activity and stability of nanosilver solution in comparison with amoxicillin antibiotic were measured and the results were examined by t-test statistical analysis. During 9 months, no significant changes were seen in antibacterial activity of nanosilver solution $\left(4000 \mu \mathrm{g} \cdot \mathrm{ml}^{-1}\right)$, except for S. mutans. In other concentrations of nanosilver solution and amoxicillin, reduction of antibacterial activity was observed.

Conclusions: Antibacterial activity of $4000 \mu \mathrm{g} \cdot \mathrm{ml}^{-1}$ nanosilver was stable in a 9 month duration but reduction of antibacterial activity in lower nanosilver concentrations and amoxicillin were significant in the same time period.
\end{abstract}

Keywords: Nanosilver Solution; Antibacterial Effects; Streptococcus mutans, Staphylococcus aureus; Pseudomonas aeruginosa

\section{Background}

Antimicrobial properties of silver compounds had been identified for a long time (1-3). In recent decades nanosilver has been welcomed because of its unique antimicrobial properties (4). Silver particles have naturally anti-inflammatory effects and also increase the power of healing $(5,6)$. It also has antimicrobial properties through effects on enzyme systems, cell wall and bacterial DNA (7). The silver particles change phosphotyrosine peptide in bacteria and subsequently change signals between the cells and ultimately prevent the proliferation of bacteria (8). However, most antimicrobial mechanisms of this material are still quite unknown (9).

Maximum exposure of silver particles in the nanosilver suspension causes increased antibacterial activity of this compound. No toxic effects on human's tissues were re- ported by low concentration of nanosilver solutions (10, 11). Nanosilver particles are effective on the bacteria Streptococcus mutans which is one of the important pathogens in dental caries, and therefore it has anti-decay effects (12-14). Staphylococcus aureus is also a cause of nosocomial and Methicillin-resistant infections which has been discussed to be important in different studies (15). Pseudomonas aeruginosa bacterium is also a problematic drug resistance bacterium which has been tested in this study to evaluate the effect of nanosilver solution against Gram-negative bacteria. There is an important question about use of new antimicrobial agents and that is about stability of these materials. It is necessary to keep the suspension stable during the product lifetime. Despite the proven antibacterial properties of nanosilver solution, information about the stability of the antimicrobial properties is negligible $(6,16,17)$. 


\section{Objectives}

That's the propose of this study to measure the antimicrobial effects of nanosilver solution against $S$. mutans, $S$. aureus and $P$. aeruginosa in 9-monthsperiod (once each 3 month) and to compare with amoxicillin antibiotic as a control agent.

\section{Materials and Methods}

For preparation of nanosilver suspension; at first silver nitrate located under reducing effects of polyaldehyde, and thus Ag+ changed to metallic Ag after receiving an electron. Silver particles tend to accumulate together and to prevent this, an acrylic polymer was used in the presence of the surface water. The effect of this surface activator reduced the silver particles tendency to stick; as a result a solution with silver particles in the nanometer size was obtained. To confirm the particle size, Intensity test was performed on the solution. Average size of silver particles was between 2-6 nanometers which were measured by DLS (dynamic light scattering) method. Microbiology testing methods: Initially in microbiology laboratory a pilot experiment was conducted to determine the antimicrobial effects of nanosilver solution against the $S$. mutans, S. aureus and P. aeruginosa bacteria, according to CLSI (Clinical and Laboratory Standard Institute) guidelines 2010 (18).

The suspensions of S. mutans (ATCC 35668), S. aureus (ATCC 29213) and P. aeruginosa (ATCC 27853) bacteria with turbidity equal of $0 / 5$ McFarland were prepared and cultured on Mueller-Hinton agar media (Pronadisa Co. Italy). Serial dilutions of nanosilver solution: 4000 $\mu$ g.ml-1(Pure), 1/10 (400 $\left.\mu \mathrm{g} \cdot \mathrm{ml}^{-1}\right), 1 / 20\left(200 \mu \mathrm{g} \cdot \mathrm{ml}^{-1}\right), 1 / 40$

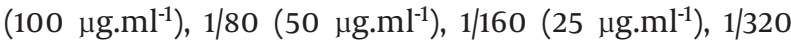
$\left(12 / 5 \mu \mathrm{g} \cdot \mathrm{ml}^{-1}\right), 1 / 640\left(6 / 25 \mu \mathrm{g} \cdot \mathrm{ml}^{-1}\right), 1 / 1280\left(3 / 125 \mu \mathrm{g} \cdot \mathrm{ml}^{-1}\right)$ and 1/2560(1/562 $\left.\mu \mathrm{g} \cdot \mathrm{ml}^{-1}\right)$ were prepared by sterile distilled water as solvent and negative control sample was also used. According to Disk diffusion method, Blank disks with 6/4 mm diameter (Padtan Teb Co. Iran) were inoculated with $15 \mu \mathrm{l}$ of the prepared nanosilver solutions and were placed on medium. Samples were incubated overnight at $35^{\circ} \mathrm{C}$. Inhibition zone were measured after 18 hours with a special ruler and results were compared with antimicrobial effects of amoxicillin antibiotic $25 \mu \mathrm{g} /$ disc (MAST Co. UK) against $S$. mutans, S. aureus and $P$. aeruginosa bacteria. This experiment was periodically performed at 0-3-6-9 months and the antibacterial stability of nanosilver solution and amoxicillin antibiotic were compared. During the nine months, the solution was kept in refrigerator at $4^{\circ} \mathrm{C}$. All experiments were performed with the proposed method according to CLSI guidelines and t-test statistical analysis was used to analyze the results.

\section{Results}

This study was done to evaluate the antimicrobial effects of nanosilver solution against three strains of $S$. mutans , $S$. aureus and $P$. aeruginosa bacteria and compare with amoxicillin as an antibiotic in 4 phases (0-3-69 months) to understand the antimicrobial changes of these antimicrobial agents by time passing. Totally the study contained 288 inhibitory zones: 66 zones for different concentration of nanosilver disks and 6 zones for amoxicillin disks in each stage.

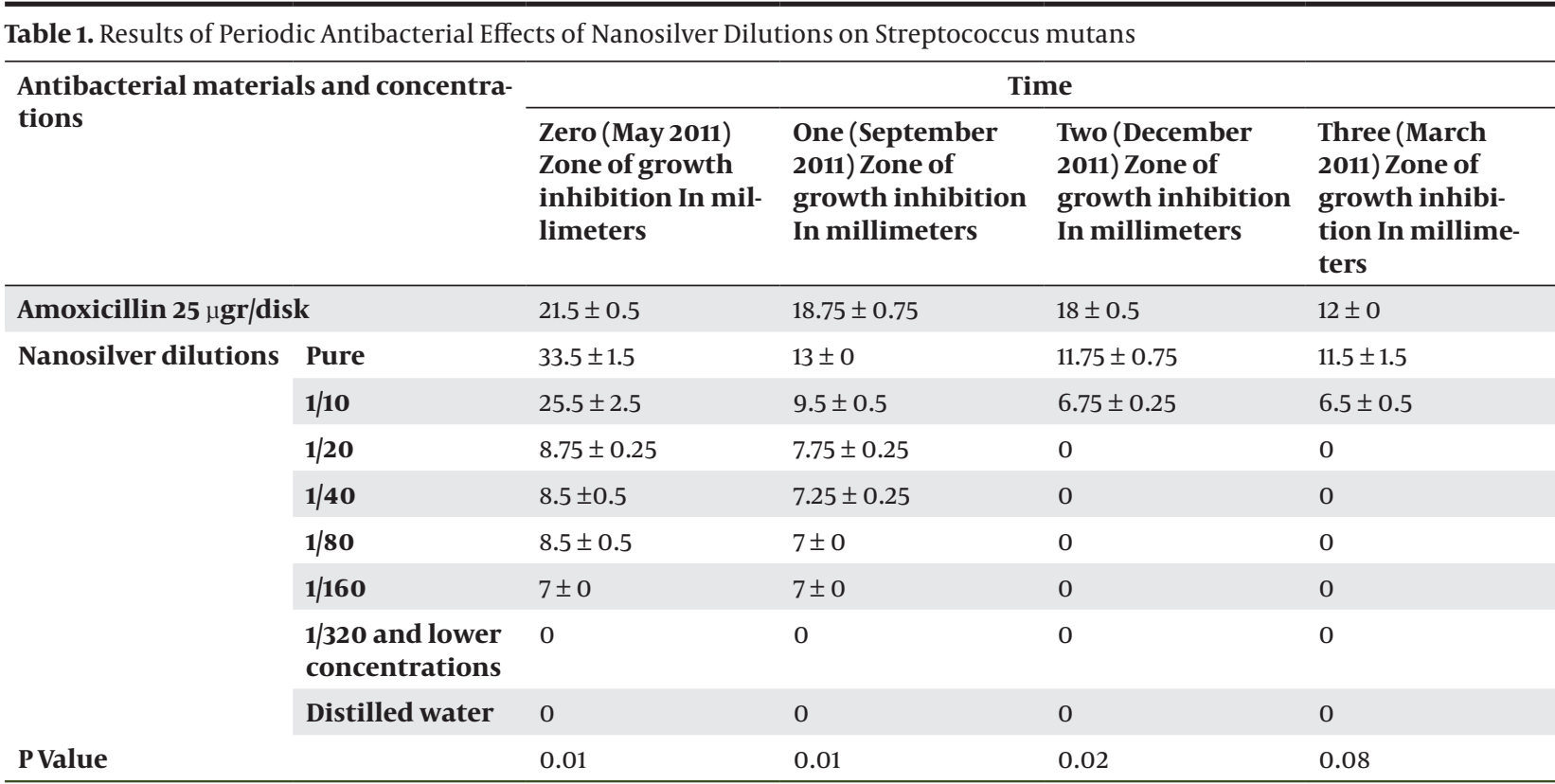


Niakan Met al.

The result of bacterial growth rate of three standard bacteria against nanosilver solution and amoxicillin according to the times of experiment are presented in Tables 1, 2, 3 and Figures 1, 2, 3, 4, 5, 6. The results show that by reducing the concentration of nanosilver its effective- ness lessens, so about nanosilver solution from concentration of 1/160 and lower bacterial inhibition zone were not observed. In all stages of the experiment, amoxicillin had no effects on P. aeruginosa growth.

Table 2. Results of Periodic Antibacterial Effects of Nanosilver Dilutions on Staphylococcus aureus

\begin{tabular}{|c|c|c|c|c|c|}
\hline \multirow{2}{*}{\multicolumn{2}{|c|}{$\begin{array}{l}\text { Antibacterial materials and concen- } \\
\text { trations }\end{array}$}} & \multicolumn{4}{|c|}{ Time } \\
\hline & & Zero (May 2011) & One (September & Two (December & Three (March \\
\hline \multicolumn{2}{|l|}{ Amoxicillin $25 \mu$ gr/disk } & $15.5 \pm 0.5$ & $13 \pm 1$ & $13.5 \pm 0.5$ & $13 \pm 1$ \\
\hline \multirow[t]{8}{*}{ Nanosilver dilutions } & Pure & $14.5 \pm 0.5$ & $15 \pm 0$ & $14.25 \pm 0.25$ & $14 \pm 1$ \\
\hline & 1/10 & $11 \pm 0$ & $11 \pm 0$ & $11.75 \pm 0.75$ & $9.5 \pm 0.5$ \\
\hline & $1 / 20$ & $9.5 \pm 0.5$ & $9 \pm 0$ & $9.75 \pm 0.25$ & $8.25 \pm 0.25$ \\
\hline & $1 / 40$ & $8 \pm 0$ & $8 \pm 0$ & $7 \pm 0$ & $7.5 \pm 0.5$ \\
\hline & $1 / 80$ & $8.25 \pm 0.25$ & 0 & 0 & 0 \\
\hline & 1/160 & 0 & 0 & 0 & 0 \\
\hline & $\begin{array}{l}1 / 320 \text { and } \\
\text { lower con- } \\
\text { centrations }\end{array}$ & 0 & 0 & 0 & 0 \\
\hline & $\begin{array}{l}\text { Distilled } \\
\text { water }\end{array}$ & 0 & 0 & 0 & 0 \\
\hline \multicolumn{2}{|l|}{ P Value } & 0.2 & 0.2 & 0.2 & 0.6 \\
\hline
\end{tabular}

Table 3. Results of Periodic Antibacterial Effects of Nanosilver Dilutions on Pseudomonas aeruginosa

\begin{tabular}{|c|c|c|c|c|c|}
\hline \multirow{2}{*}{\multicolumn{2}{|c|}{$\begin{array}{l}\text { Antibacterial materials and concentra- } \\
\text { tions }\end{array}$}} & \multicolumn{4}{|l|}{ Time } \\
\hline & & \multirow{2}{*}{$\begin{array}{l}\text { Zero (May 2011) } \\
\text { Zone of growth } \\
\text { inhibition In } \\
\text { millimeters }\end{array}$} & \multirow{2}{*}{$\begin{array}{l}\text { One (September } \\
\text { 2011) Zone of } \\
\text { growth inhibi- } \\
\text { tion In millime- } \\
\text { ters }\end{array}$} & \multirow{2}{*}{$\begin{array}{l}\text { Two (December } \\
\text { 2011) Zone of } \\
\text { growth inhibi- } \\
\text { tion In millime- } \\
\text { ters }\end{array}$} & \multirow{3}{*}{$\begin{array}{l}\text { Three (March } \\
\text { 2011) Zone of } \\
\text { growth inhibi- } \\
\text { tion In millime- } \\
\text { ters } \\
0\end{array}$} \\
\hline \multirow{2}{*}{\multicolumn{2}{|c|}{ Amoxicillin $25 \mu \mathrm{gr} /$ disk }} & & & & \\
\hline & & 0 & 0 & 0 & \\
\hline \multirow[t]{8}{*}{ Nanosilver dilutions } & Pure & $15 \pm 1$ & $14 \pm 0$ & $15 \pm 0$ & $14.25 \pm 0.25$ \\
\hline & $1 / 10$ & $11 \pm 0$ & $11 \pm 0$ & $11 \pm 0$ & $8.75 \pm 0.25$ \\
\hline & $1 / 20$ & $9 \pm 0$ & $8 \pm 0$ & $8 \pm 0$ & $8 \pm 0.5$ \\
\hline & $1 / 40$ & $9 \pm 0.5$ & $8 \pm 0$ & $8.25 \pm 0.25$ & $7.5 \pm 0$ \\
\hline & $1 / 80$ & $9.5 \pm 0.5$ & 0 & 0 & 0 \\
\hline & $1 / 160$ & 0 & 0 & 0 & 0 \\
\hline & $\begin{array}{l}1 / 320 \text { and lower } \\
\text { concentrations }\end{array}$ & 0 & 0 & 0 & 0 \\
\hline & Distilled water & 0 & 0 & 0 & 0 \\
\hline \multicolumn{2}{|l|}{ P Value } & 0.01 & 0.001 & 0.001 & 0.001 \\
\hline
\end{tabular}


Niakan Met al.

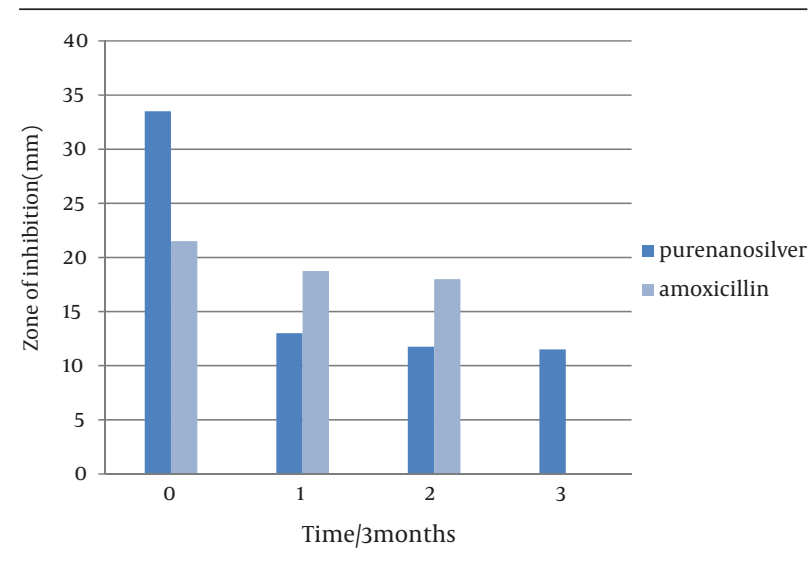

Figure 1. Results of Periodic Antibacterial Effects of Pure Nano silver Solution on Streptococcus mutan

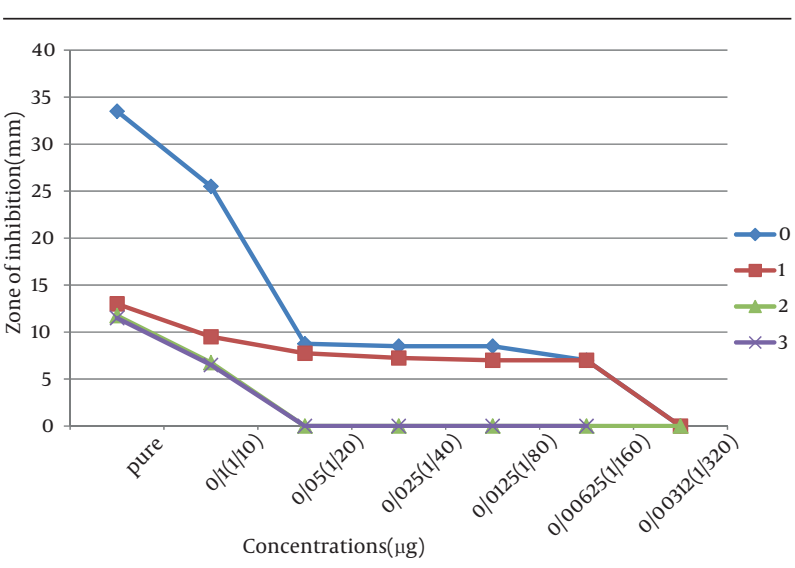

Figure 2. Results of Periodic Antibacterial Effects of Nanosilver Concentrations on Streptococcus mutans

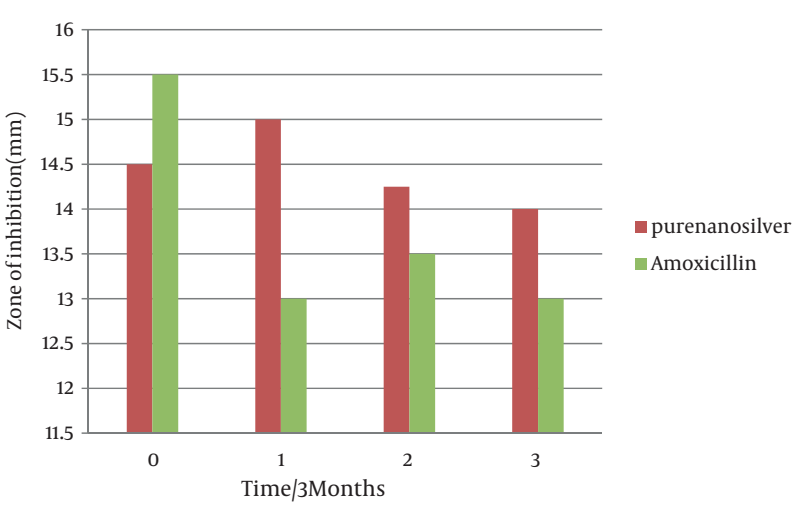

Figure 3. Results of Periodic Antibacterial Effects of Pure Nanosilver Solution on Staphylococcus aureus

In the first stage (time zero), the effects of nanosilver were greater than amoxicillin on the bacteria S. mutans and $P$. aeruginosa . T-test statistical analysis confirmed that inhibition zones of two antibacterial materials were different.

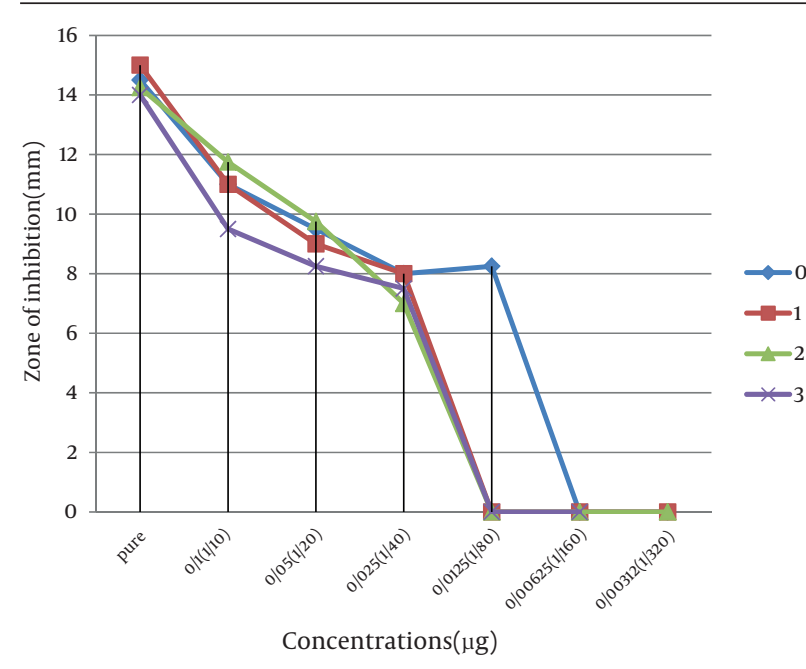

Figure 4. Results of Periodic Antibacterial Effects of Nano silver Concentrations on Staphylococcus aureus

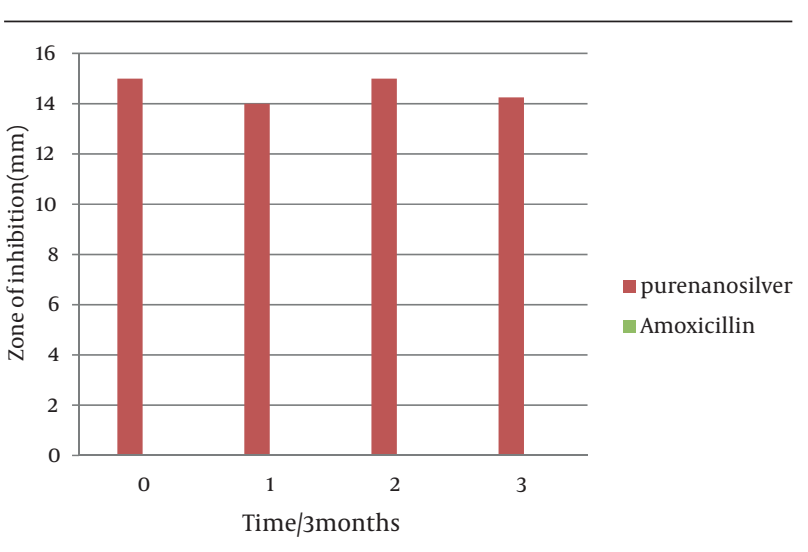

Figure 5. Results of Periodic Antibacterial Effects of Pure Nanosilver Solution on Pseudomonas aeruginosa

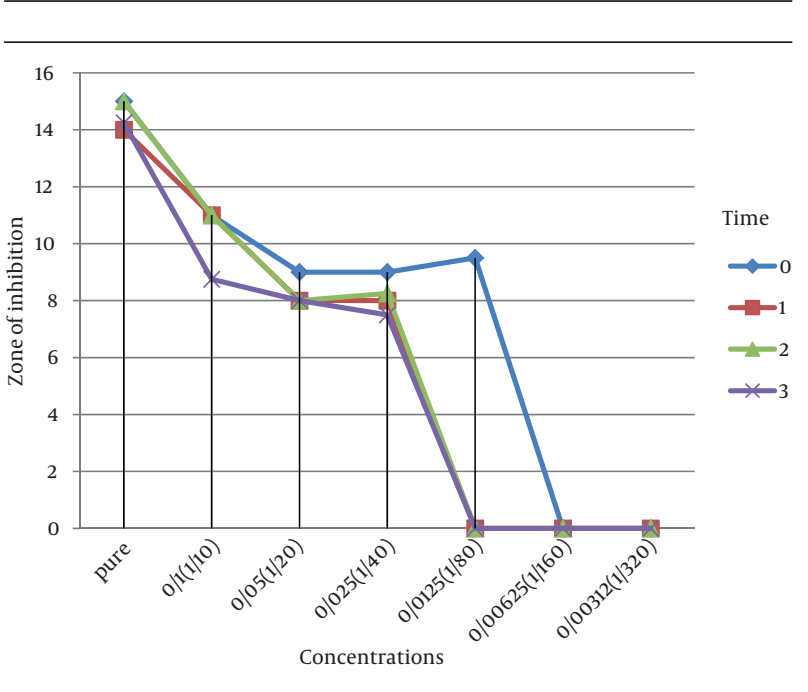

Figure 6. Results of Periodic Antibacterial Effects of Nano silver Dilutions on Pseudomonas aeruginosa 
Tukey test showed that nanosilver was the best antibacterial material in this study (Figures 1 and 2). In S. aureus bacteria plates, in the first stage the antibacterial effects of amoxicillin were more. T-test statistical analysis also confirmed inhibition zones of two antibacterial materials were different and Tukey test confirmed the antibacterial effects of amoxicillin were the best (Table 2, Figures $3,4)$.

In the first three months follow up (time 1) in S. aureus and $P$. aeruginosa bacteria, nanosilver antibacterial effects were better than amoxicillin. T-test statistical analysis confirmed that zone of two antibacterial materials were different and Tukey test showed that nanosilver was the best antibacterial material in this time period (Tables 2 and 3). In bacteria S. mutans at this stage, the antibacterial effect of amoxicillin was more than nanosilver effect. Ttest statistical analysis confirmed that inhibition zone of two antibacterial materials were different and Tukey test confirmed the antibacterial effects of amoxicillin was the best (Table 1, Figure 1). The results of the first follow up were repeated in the second (month 6) and third (month 9) follow-ups (Tables 1, 2, 3 and Figures 1, 3, 5).

\section{Discussion}

According to the results of the study no changes in antimicrobial effects of pure nanosilver solution were observed, except against S. mutans. Results indicate the high stability of the antimicrobial properties of this new product against bacteria during the study time. The range of antimicrobial activity of nanosilver solution against $S$. mutans in the first and second phases of the study was from pure to $1 / 160$ dilution. In seems that by passing the time, the high concentrations were less effective and the low concentrations have lost their antimicrobial activity against $S$. mutans. Reduction in antimicrobial activity of amoxicillin against $S$. mutans was also remarkable.

The antimicrobial activity of nanosilver solution against $S$. aureus in the first phase of the study was from pure to 1/80 dilution. In the second, third and fourth phases, the range of antimicrobial activity were between pure to 1/40 dilution. So there was a slight decrease in antimicrobial activity of the dilutions. Reduction of antimicrobial effect of amoxicillin against S. aureus was also slight. Amoxicillin was not effective against $P$. aeruginosa. The range of antimicrobial activity of nanosilver solution against $P$. aeruginosa in the first phase of the study was from pure to $1 / 80$ dilution. In the second, third and fourth phases, the range of antimicrobial activity were between pure to 1/40 dilution. Totally there was a slight decrease in antimicrobial activity of nanosilver solution against $P$. aeruginosa.

Few studies have been conducted to evaluate the antimicrobial stability of nanosilver and the major goals of them were to study the stability of silver nanoparticles' size, deposition and retention on surfaces. Yan and Chong (2002-USA) study on nanosilver colloidal solution containing nanosilver particles with the size between 1 to $100 \mathrm{~nm}$, investigated size and stability of nanosilver colloidal solution. In Yan study the size and stability of nanosilver particles in fresh solution was compared with the solution which was maintained at room temperature for study time. The size of particles did not change and they were not deposited after 110 days (19). In our study, we showed the effects of nanosilver particles not based on their shape, but due to their antibacterial effects and despite the different ways of nanosilver preparation, the results of our study was consistent with the mentioned study. In Kim et al. study, antimicrobial effect and stability of nanosilver particles bonded with silica Nanoparticles (NSS) produced by using Gamma rays at room temperature, was evaluated by using the fungus growth. Antifungal effects of silver nanoparticles were stable for at least 24 months (20) that was consistent with the results of our study during nine months.

In another study conducted by Lin and colleagues a hyper branch polymer was used to measure the mechanical anti-microbial stability of nanosilver particles. It was shown that $12 \mathrm{~nm}$-nanosilver particles maintain up to $94 \%$ of their antimicrobial properties against bacteria, S.aureus and Escherichia coli subsequent 50 times washing up (21). Lin et al. examined properties of nanosilver particles durability that is somewhat consistent with our study. However, Hong Lin investigated antimicrobial properties of nanosilver against two strains of bacteria and more emphasis was on the physical stability, but we tested antibacterial properties of nanosilver solution on three strains of bacteria in duration of nine months.

The Lei study showed that the stability properties of nanosilver suspension is highly dependent on the environment $\mathrm{PH}$ (22), while in our study time was the main variable. In this study the antimicrobial effects of nanosilver were measured against three species of bacteria. Antibacterial stability of nanosilver solution was remarkable against S. aureus and P. aeruginosa. Reduction of antibacterial properties were observed in lower concentrations of nanosilver and control antibiotic. In this case, additional information was not obtained from other studies, it can be stated that this was a new kind of research and further studies is needed to evaluate different properties of this product in long-time and the results can be used in the formulation and design of health materials and antimicrobial drugs producing by silver nanoparticles.

\section{Acknowledgements}

We thank Research Center for Nano medicine in Dentistry, Dentistry Faculty, Herbal Medicine research center of Shahed University, Dr Najafi F and Dr Fatemi M for support this project.

\section{Authors' Contribution}

None declared 


\section{Financial Disclosure}

\author{
By Laboratory Examination
}

\section{Funding/Support}

By Research Department.

\section{References}

1. Klasen HJ. Historical review of the use of silver in the treatment of burns. I. Early uses. Burns. 2000;26(2):117-30.

2. Silver S, Phung LT. Bacterial heavy metal resistance: new surprises. Annu Rev Microbiol.1996;50:753-89.

3. Slawson RM, Van Dyke MI, Lee H, Trevors JT. Germanium and silver resistance, accumulation, and toxicity in microorganisms. Plasmid.1992;27(1):72-9.

4. ADA Council on Dental Materials and Devices. JADA 2008. p. 673-7.

5. Jung WK, Koo HC, Kim KW, Shin S, Kim SH, Park YH. Antibacterial activity and mechanism of action of the silver ion in Staphylococcus aureus and Escherichia coli. Appl Environ Microbiol. 2008;74(7):2171-8.

6. Chaloupka K, Malam Y, Seifalian AM. Nanosilver as a new generation of nanoproduct in biomedical applications. Trends Biotechnol. 2010;28(11):580-8

7. Brown TA, Smith DG. The effects of silver nitrate on the growth and ultra-structure of the yeast Cryptococcusus albidus. Microbios Lett. 1976;3(11-12):155-62.

8. Shrivastava S, Bera T, Singh SK, Singh G, Ramachandrarao P, Dash D. Characterization of antiplatelet properties of silver nanoparticles. ACS Nano. 2009;3(6):1357-64.

9. Safavi K, Esfahanizadeh M, Mortazaeinezahad DH, Dastjerd H The study of nano silver (NS) antimicrobial activity and evaluation of using NS in tissue culture media. Etlibrary. 2011;3:159-61.

10. Panyala NR, Peña-Méndez EM, Havel J. Silver or silver nanoparticles: a hazardous threat to the environment and human health.J Appl Biomed. 2008;6(3):117-29.

11. Jo YK, Kim BH, Jung G. Antifungal activity of silver ions and nanoparticles on phytopathogenic fungi. Plant Dis. 2009;93(10):1037-43.

12. Hernandez-Sierra JF, Ruiz F, Pena DC, Martinez-Gutierrez F, Martinez AE, Guillen Ade J, et al. The antimicrobial sensitivity of Streptococcus mutans to nanoparticles of silver, zinc oxide, and gold Nanomedicine. 2008;4(3):237-40.

13. Klein MI, DeBaz L, Agidi S, Lee H, Xie G, Lin AH, et al. Dynamics of Streptococcus mutans transcriptome in response to starch and sucrose during biofilm development. PLoS One. 2010;5(10): e13478.

14. Caufield PW, Dasanayake AP, Li Y, Pan Y, Hsu J, Hardin JM. Natural history of Streptococcus sanguinis in the oral cavity of in fants: evidence for a discrete window of infectivity. Infect Immun. 2000;68(7):4018-23.

15. Ossowski K, Chun RH, Suskind D, Baroody FM. Increased isolation of methicillin-resistant Staphylococcus aureus in pediatric head and neck abscesses. Arch Otolaryngol Head Neck Surg. 2006;132(11):1176-81.

16. Singh M, Singh S, Prasad S, Gambhir IS. Nanotechnology in medicine and antibacterial effect of silver nanoparticles. Digest J Nanomater Biostructures . 2008;3(3):115-22.

17. Poveda Roda R, Bagan JV, Sanchis Bielsa JM, Carbonell Pastor E. Antibiotic use in dental practice. A review. Med Oral Patol Oral Cir Bucal. 2007;12(3):E186-92.

18. Performance standards for Antimicrobial susceptibility testing, twentieth informational supplement, Clinical and Laboratory Standard Institute (CLSI). 2010.p. 3-5.

19. Yan J, Cheng J. Colloidal nanosilver solution and method for making the same. 2002

20. Kim HJ, Park HJ, Choi SH. Antimicrobial action effect and stability of nanosized silica hybrid Ag complex. J Nanosci Nanotechnol. 2011;11(7):5781-7.

21. Lin H, Chen L, Zhang D, Chen Y. Silver Nanoparticles by AminoTerminated Hyper branched Polymer: Characterization and Antimicrobial Property on Cotton. Advanced Materials Res. 2011;930:332-4.

22. Lei G. Synthesis of Nano-Silver Colloids and Their Anti-Microbial Effects. 2007 